\title{
Surgical creation of a double outlet right atrium for tricuspid valve stenosis after a Rastelli operation
}

\author{
JOHN E DEANFIELD, STEVEN R GUNDRY, JAROSLAV STARK \\ From the Cardiothoracic Unit, The Hospital for Sick Children, London
}

SUMMARY A patient with transposition of the great arteries, ventricular septal defect, and obstruction of the left ventricular outflow tract underwent a Rastelli repair. Stenosis of th tricuspid valve was not recognised before or during operation; this severely compromised the postoperative haemodynamic function and necessitated reoperation. Insertion of a second homograft from the right atrium to the right ventricle bypassed the stenosis and resulted in 8 complete recovery with maintenance of a biventricular circulation.

The Rastelli operation ${ }^{1}$ remains the operation of choice for patients with transposition of the great arteries with a ventricular septal defect and obstruction of the left ventricular outflow tract. Preoperative assessment of the size and position of the ventricular septal defect, the size of both ventricular chambers, size and structure of both atrioventricular valves, and the pulmonary arteries is important because an abnormality of any of these structures may preclude a successful outcome.

We have recently operated upon a child with transposition of the great arteries, ventricular septal defect, and obstruction of the left ventricular outflow tract in whom assessment before and during operation did not lead to the diagnosis of tricuspid valve stenosis. This stenosis severely compromised postoperative haemodynamic function. The patient was reoperated upon early in the postoperative course once the problem was recognised, and a second homograft was inserted between the right atrium and right ventricle.

\section{Case report}

The patient was born after a normal pregnancy and delivery. Cyanosis was noted at the age of one and became progressively worse over the next few years. Transposition of the great arteries, ventricular septal defect, and obstruction of the left ventricular outflow tract were diagnosed by cardiac catheterisation and angiocardiography. When he was seven he was referred for further evaluation and operation.

Requests for reprints to Dr John E Deanfield, Cardiothoracic Unit, The Hospital for Sick Children, Great Ormond Street, London WC1N 3JH.
Clinical examination on admission was compatible with the diagnosis. Further investigation including cross sectional echocardiography, cardiac catheter- -0 isation, and angiocardiography confirmed the diag .0 nosis of transposition of the great arteries, ventricular. septal defect, with severe subvalvar obstruction of the left ventricular outflow tract. No pressurb gradients were detected between the right and lefo atria (table) or across the atrioventricular valves. I $\mathbb{R}$ was decided to proceed with a Rastelli operation.

\section{OPERATION}

The operation was performed during hypothermie $\left(20^{\circ} \mathrm{C}\right)$ cardiopulmonary bypass with aortic cross clamping (50 min) and cardioplegic protection with St Thomas' solution. The tricuspid valve could not be visualised adequately and so the annulus was not measured. This was the result of the rotation of the heart to the right. As there was no angiographic op echocardiographic evidence of a tricuspid valve

Table Pressure data at cardiac catheterisation

\begin{tabular}{|c|c|c|c|}
\hline $\begin{array}{l}\text { Pressure } \\
\text { data }\end{array}$ & Preoperative & $\begin{array}{l}\text { After } \\
\text { Rastelli }\end{array}$ & $\begin{array}{l}\text { After } \\
R A-R V \text { conduit }\end{array}$ \\
\hline$\overline{\mathbf{R A}}$ & $\begin{array}{ll}a=9 & \overline{8} \\
v=9 & \end{array}$ & $\begin{array}{l}a=24 \\
v=23\end{array}$ & $\overline{14}$ \\
\hline $\begin{array}{l}\text { RV } \\
\text { PA }\end{array}$ & $\begin{array}{l}87 / 0-8 \\
18 / 12 / 14\end{array}$ & $\begin{array}{l}36 / 4-11 \\
19 / 11 / 13\end{array}$ & $\begin{array}{l}23 / 4-14 \\
19 / 14 / 16\end{array}$ \\
\hline LA & $\begin{array}{ll}a=9 & \overline{8} \\
v=9 & \end{array}$ & (PCW) 9 & $(\mathrm{PCW}) 10$ \\
\hline $\begin{array}{l}\text { LV } \\
\text { Ao }\end{array}$ & $\begin{array}{l}86 / 0-10 \\
84 / 57 / 69\end{array}$ & $\begin{array}{l}\text { NE } \\
80 / 46 / \overline{54}\end{array}$ & $\begin{array}{l}\text { NE } \\
91 / 51 / \overline{63}\end{array}$ \\
\hline
\end{tabular}

Pressures are given as systolic/diastolic/mean in Ao and PA; systolicД diastolic in $\mathbf{R V}$ and $\mathbf{L V}$.

Ao, aorta; LA, left atrium; LV, left ventricle; NE, not entered; PA pulmonary artery; PCW, pulmonary capillary wedge; $R A$, righ atrium; RV, right ventricle. 


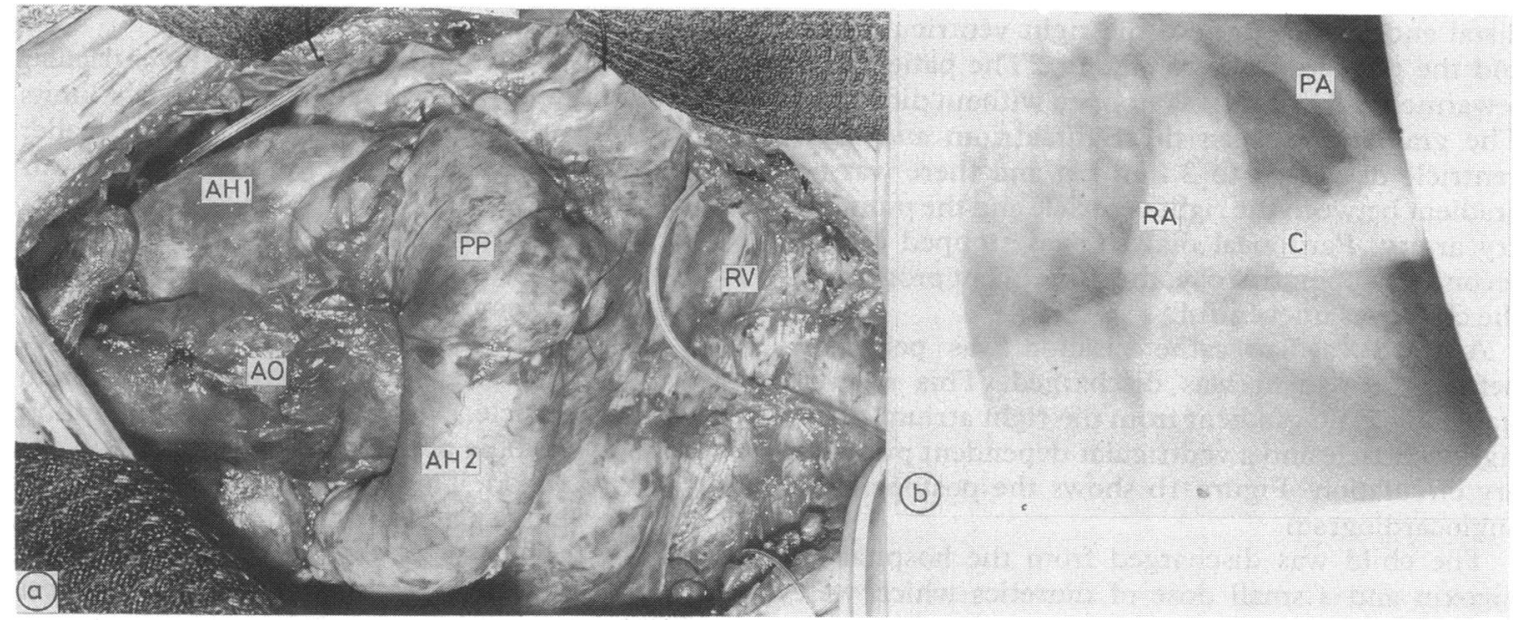

Fig 1 (a) Operative picture showing the two homografts and pericardial patch in place. AH1, first aortic homograft between the right ventricle and the pulmonary artery; $A H 2$, second homograft between the right atrium and the right ventricle; $A O$, aorta; PP, pericardial patch; $R V$, right ventricle. (b) Angiogram showing right atrium ( $R A)$ to right ventricle conduit (C) after the second operation. $P A$, pulmonary artery.

abnormality no special effort was made to see the valve and measure the annulus. A right ventriculotomy was performed and a standard Rastelli procedure was carried out with a $21 \mathrm{~mm}$ antibiotic sterilised aortic valved homograft. At completion of the operation the right atrial pressure was raised and there was a $9 \mathrm{~mm} \mathrm{Hg}$ gradient between the right atrium and the right ventricle at end diastole. The systolic gradient from the right ventricle to the pulmonary artery $(17 \mathrm{~mm} \mathbf{H g})$ was regarded as unimportant. The child was returned to the intensive care unit, intubated, and ventilated on inotropic support. His condition, however, gradually deteriorated over the next few hours and severe right heart failure with hepatomegaly and ascites developed. He went into progressive renal failure that required peritoneal dialysis. In view of the failure of medical treatment and the persistently high right atrial pressure, cardiac catheterisation was repeated (table). This confirmed the presence of a persistent gradient between the right atrium and the right ventricle at end diastole $(9 \mathrm{~mm} \mathrm{Hg})$ with an additional $17 \mathrm{~mm} \mathrm{Hg}$ gradient from the right ventricle to the pulmonary artery. Review of both angiocardiography and echocardiography showed that the tricuspid valve annulus was small $(<95 \%$ confidence limits for the patient's body surface area), and this was felt to be the main reason for the poor haemodynamic function.

The child was returned to the operating theatre 14 hours after the completion of the first repair. The right atrium was opened on cardiopulmonary bypass with moderate hypothermia $\left(28^{\circ} \mathrm{C}\right)$, without aortic cross clamping. The tricuspid valve was found to be small but of normal appearance. The previous right ventricle to pulmonary artery aortic homograft was partially detached from the right ventricular outflow tract and this area was enlarged with a generous pericardial patch. A second antibiotic preserved 18 mm aortic valved homograft was then sutured with its "ventricular end" to the right atriotomy and its
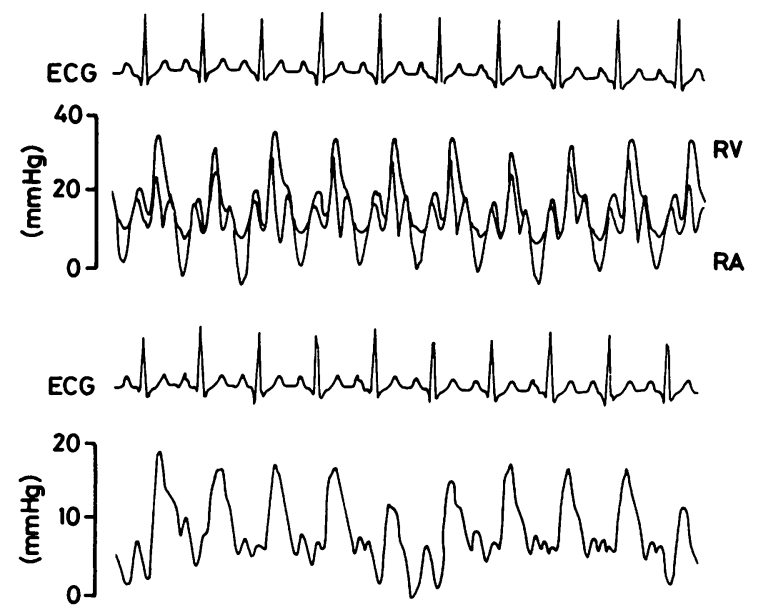

Fig 2 (Top) Pressure tracing showing no gradient at cardiac catheterisation between the right atrium and right ventricle after insertion of the right atrium to right ventricle conduit. (Bottom) A "ventricular dependent" pulmonary artery pressure tracing obtained during the same investigation. 
distal end to the edges of the right ventriculotomy and the pericardial patch (fig 1a). The patient was rewarmed and bypass was stopped without difficulty. The gradient between the right atrium and right ventricle decreased to $2 \mathrm{~mm} \mathrm{Hg}$ and there was no gradient between the right ventricle and the pulmonary artery. Peritoneal dialysis was stopped on the second postoperative day; the subsequent progress of the child was uneventful.

A third cardiac catheterisation was peformed before the patient was discharged. This showed (table, fig 2) no gradient from the right atrium to the right ventricle and a ventricular dependent pulmonary circulation. Figure $1 \mathrm{~b}$ shows the postoperative angiocardiogram.

The child was discharged from the hospital on digoxin and a small dose of diuretics which were stopped after four weeks. His subsequent progress was excellent with no evidence of right or left sided heart failure over the next two years.

\section{Discussion}

Severe stenosis or hypoplasia of the tricuspid valve is one of the contraindications to the Rastelli operation. ${ }^{2}$ Tricuspid valve stenosis was missed in our case both before and during operation. It is likely that the condition was not diagnosed at preoperative cardiac catheterisation because the large atrial and ventricular septal defects allowed equalisation of atrial pressures and obscured any end diastolic gradient across the tricuspid valve. The tricuspid valve had a normal configuration on both echocardiogram and direct inspection, through the ventriculotomy, and the degree of stenosis was not recognised until review at the second operation. The diagnosis became obvious after the child's condition deteriorated during the first postoperative hours, and was confirmed at recatheterisation.

As for any other operation, the atrioventricular $c^{c}$ valve needs to be within the $95 \%$ confidence limits for the patient's body surface area. If it is smallero severe problems, such as those that developed in our음 patient, may occur.

There are two options when the tricuspid valve is $\frac{\widehat{D}}{\Phi}$ too small. Firstly, the orifice can be closed and and atriopulmonary connection can be established (Fontan procedure). ${ }^{3}$ Secondly, the stenosis can be by-. passed with a valved conduit from the right atrium to $\overrightarrow{-}$ the right ventricle. We chose the second option because this had the potential of producing a biventricular circulation. This was confirmed after opera- 8 tion by the ventricular dependent pulmonary artery tracing (fig 2). We also felt that the second option wasa simpler and shorter operation for a child in a critical $N$ condition.

This case illustrates the need for scrupulousevaluation of all patients who are to be considered for a Rastelli operation. We suggest that two conduits can be used when valvar obstruction is present at $\stackrel{\text { क }}{\oplus}$ both atrioventricular and ventriculoarterial levels. $\vec{\oplus}$ We believe that this solution preserves ventricular $\infty$ contribution to anterograde blood flow and is preferable to an atriopulmonary connection.

\section{References}

1 Rastelli GC. A new approach to "anatomic" repair of transposition of the great arteries. Mayo Clin Procô 1969;44:1-12.

2 Huhta JC, Edwards WD, Danielson GK, Feldt, RH.尹 Abnormalities of the tricuspid valve in complete? transposition of the great arteries with ventricular septal defect. J Thorac Cardiovasc Surg 1982;83: $569-76$.

3 Fontan F, Baudet E. Surgical repair of tricuspid atresia. Thorax 1971;26:240-8. 